\title{
Molecular type and maximal metastasis diameter influence risk of axillary recurrence in breast cancer patients after positive sentinel lymph node biopsy
}

\author{
Michał Falco ${ }^{1}$, Bartłomiej Masojć ${ }^{1}$, Andrzej Kram ${ }^{2}$ \\ ${ }^{1}$ Radiation Oncology Department, West Pomeranian Oncology Center, Szczecin, Poland \\ ${ }^{2}$ Pathology Department, West Pomeranian Oncology Center, Szczecin, Poland
}

\begin{abstract}
Background: Breast cancer patients with positive sentinel lymph node biopsy (SLNB) may be spared axillary lymph node dissection (ALND) in favour of irradiation. The aim of the study was to estimate local control probability in the axilla (axLCP).

Materials and methods: We identified 1832 invasive breast cancer patients who had undergone SLNB at our centre. We measured maximal metastasis diameter (SLDmax) in the sentinel lymph nodes and lymph node metastasis volume (VALN) from ALND in 246 patients with one or two positive SLNs. We calculated axLCP after irradiation and systemic treatment for different molecular types.

Results: VALN values are higher for high grade tumours and larger metastases in SLNs (> $5 \mathrm{~mm})$. It is smaller in luminal A tumours. axLCP is high, nearly 100\%, in all molecular types in radiation sensitive tumours (SF2 Gy $=0.45$ ), except luminal B. Expected axLCP is relatively low (67\%) in luminal B radiation sensitive tumours with no chemotherapy and nearly $100 \%$ with chemotherapy.

Conclusion:VALN values differ among molecular tumour types. They depend on SLNDmax and tumour grade. New prognostic factors are needed for selected luminal B breast cancer patients (i.e. high grade tumours, large metastases in SLNs) after positive SLNB intended to be spared ALND and chemotherapy.
\end{abstract}

Key words: breast cancer; sentinel lymph node; radiotherapy; axillary lymph node dissection; prognostic factor

Rep Pract Oncol Radiother 2021;26(5):785-792

\section{Introduction}

Sentinel lymph node biopsy (SLNB) is an important procedure in the management of breast cancer patients with clinically negative ipsilateral axillary lymph nodes. Multiple trials show that axillary lymph node dissection (ALND) and irradiation are unnecessary if there is either no metastasis $[1,2]$ or micrometastasis $[3,4]$ in the resected sentinel lymph node (SLN).
Two randomised trials, ACOSOG Z011 and AMAROS, compared ALND and axillary irradiation in patients with metastasis in SLN $[5,6]$. In both trials, nearly $60 \%$ of enrolled patients had macrometastases in one or two SLNs. The results did not differ significantly if either ALND or irradiation were implemented. Irradiation used instead of ALND leads to lower toxicity because fewer patients have arm lymphoedema [4, 6] and neuropathy [4]. Following the results of these trials, the recommenda-

Address for correspondence: Michał Falco, Radiation Oncology Department, West Pomeranian Oncology Center, Strzałowska 22, 71-730 Szczecin, Poland; e-mail: mfalco@onkologia.szczecin.pl 
tions suggest applying irradiation to the ipsilateral axillary fossa and avoiding ALND in breast cancer patients with pT1-2 tumours with no prior systemic treatment and metastases in 1-2 SLNs $[7,8]$.

Almost two-thirds of patients in the ACOSOG Z011 and AMAROS trials underwent chemotherapy $[5,6]$. Based on current standards, chemotherapy is recommended for breast cancer patients with Her-2/neu overexpression and triple-negative tumours, and for a selected group of patients with luminal-type tumours and involved axillary lymph nodes $[7,8]$. Patients with luminal-type tumours and three or less involved axillary lymph nodes should be qualified to chemotherapy following multigene assay risk factor analysis [7]. Based on current standards, less breast cancer patients are offered chemotherapy.

Information on tumour biology in the ACOSOG Z011 and AMAROS trials is limited. The ACOSOG Z011 trial reported information only on oestrogen receptor (ER) positivity (nearly $82 \%$ of patients) $[5,6]$. In an earlier publication, we presented data that showed significant differences in the tumour volume in the axillary lymph nodes after positive SLNB in different breast cancer molecular types (luminal A vs. luminal B vs. triple-negative vs. Her-2/neu overexpression) [9].

The aim of this study was to estimate local control probability after axillary irradiation without ALND in different treatment scenarios for different molecular subtypes (Luminal A vs Luminal B vs triple negative vs Her-2/neu overexpression tumours), use of systemic treatment methods (hormonal treatment, chemotherapy) and levels of radiation sensitivity in breast cancer patients macrometastses in 1 or 2 SLNs.

\section{Materials and methods}

Between May 2006 and December 2013 we identified 1832 invasive breast cancer patients who had undergone the SLNB procedure at our centre. All patients underwent operation as a primary procedure. Ultrasound examination of the axilla was performed in every patient before operation. One to nine sentinel lymph nodes per patient were resected (mean value 1.8 , median 1 ). In the analysed cohort positive SLNs (metastatic) were detected in 451 cases $(24.6 \%)$. Sixty patients did not undergo axillary lymphadenectomy despite the fact that the metastases were present in resected SLNs, due to patient refusal. In $20(33.3 \%)$ cases there were micrometastases in SLNs and macrometastases were present in $40(66.6 \%)$ cases. Those with macrometastases underwent adjuvant irradiation according to results of ACOSOG Z011 trial results [5]. Three hundred ninety-one patients from the SLN-positive group additionally underwent ALND, and in 157 cases $(40.2 \%)$ further positive lymph nodes (metastatic) were present.

The specimens of those 391 patients were further analysed. An experienced pathologist reviewed lymph node specimens from SLN-positive cases and lymph node specimens after ALND. For each patient, reference specimens of positive SLNs and ALNs were selected. The specimens were scanned with an AperioScanScope AT Turbo scanner (Aperio, Vista, CA, USA). In 323 cases (82.6\%), we were able to gather images for the sentinel and axillary lymph nodes. Percentage of lost data was comparable in both groups with and without metastases to the axillary lymph nodes ( $19.8 \%$ vs $15.9 \%)$. We excluded from analysis 64 cases $(19.9 \%)$ with micrometastases in SLNs and 13 cases (4\%) with macrometastases in 3 or more SLNs. The analysis was further conducted on remaining 246 cases $(76.1 \%)$ with macrometastses in 1 or 2 SLNs.

Scanned images of lymph nodes were further analysed with the AperioImageScope software (Aperio, Vista, CA, USA). Areas of tumour foci were contoured and the surface of infiltration for every field was calculated. Based on the circle area formula $\left(A=\pi r^{2}\right)$, the radius for every tumour focus was calculated and volume estimated $\left(\mathrm{V}={ }^{4} /{ }_{3} \pi \mathrm{r}^{3}\right)$. Volumes of tumour foci were then summed in each case (every patient separately for the sentinel and axillary lymph nodes). Finally we obtained tumour volume in the remaining axillary lymph nodes $\left(\mathrm{V}_{\mathrm{ALN}}\right.$, expressed in $\left.\mathrm{mm}^{3}\right)$ and metastasis diameter in SLNs (SLN Dmax $_{\text {max }}$ expressed in $\mathrm{mm}$ ) for 246 breast cancer patients with macrometastases in one or two SLNs.

An independent-sample $t$-test was used to compare mean $V_{\text {ALN }}$ values for different risk factors (Tab. 1). Those factors were age ( $\leq 40$ y vs. $40-60$ y vs. $\geq 60 \mathrm{y}$ ), tumour size (pT1a-b vs. pT1c vs. pT2), tumour type (NST grade I, tubular vs. NST grade II vs. NST grade III $v s$. Lobular cancer), ER receptor (present $v s$. negative), Her2/neu receptor (no vs. overexpression), molecular type (luminal 
Table 1. Correlation of mean VALN and selected predictive factors

\begin{tabular}{|c|c|c|}
\hline & Numbe & Mean $V_{\text {ALN }}$ \\
\hline \multicolumn{3}{|l|}{ Age } \\
\hline$\leq 40 y$ & 14 & $70.84(-8.3-149.99)$ \\
\hline$>40 y<60 y$ & 141 & $132.3(59-205.63)$ \\
\hline$\geq 60 y$ & 91 & $163.88(43.84-283.92)$ \\
\hline \multicolumn{3}{|c|}{$\leq 40 y$ vs. $>40 y<60 y, N S ;>40 y<60 y$ vs. $\geq 60 y, N S ; \leq 40 y$ vs $\geq 60 y$, NS } \\
\hline \multicolumn{3}{|l|}{ Tumour size } \\
\hline pT1a-b & 28 & $15.36(-4.98-35.7)$ \\
\hline pT1c & 128 & $125.32(44.48-206.17)$ \\
\hline pT2 & 87 & $207.89(83.49-332.3)$ \\
\hline \multicolumn{3}{|c|}{ pT1a-b vs. pT1c, NS; pT1a-b vs. pT2, NS; pT1c vs. pT2, NS } \\
\hline \multicolumn{3}{|l|}{ Tumour type } \\
\hline NST I,t & 19 & $13.12(-12.51-38.74)$ \\
\hline NST II & 115 & $61.96(33.17-90.76)$ \\
\hline NST III & 65 & $301.98(113.75-490.21)$ \\
\hline Lobular & 39 & $99.07(19.5-178.64)$ \\
\hline \multicolumn{3}{|c|}{ NST I,t vs. NST II, NS; NST I,t vs. NST III, NS; NST III vs. lobular, NS; NST II vs. NST III, p= 0.0013} \\
\hline \multicolumn{3}{|l|}{ ER } \\
\hline Positive & 203 & $121.87(59.12-184.62)$ \\
\hline Negative & 41 & $239.48(43.72-435.25)$ \\
\hline \multicolumn{3}{|l|}{ Positive vs. Negative, NS } \\
\hline \multicolumn{3}{|l|}{ Her2/neu } \\
\hline No & 205 & $137.34(65.79-208.89)$ \\
\hline Yes & 37 & $173.09(89.96-256.22)$ \\
\hline \multicolumn{3}{|l|}{ No vs. Yes, NS } \\
\hline \multicolumn{3}{|l|}{ Molecular type } \\
\hline Luminal A & 90 & $30.17(7.01-53.34)$ \\
\hline Luminal B & 73 & $263.74(95.83-431.65)$ \\
\hline Her2/neu overexpression & 37 & 173.09 (89.96-256.22) \\
\hline TNBC & 24 & $233.75(-93.82-561.33)$ \\
\hline \multicolumn{3}{|c|}{$\begin{array}{l}\text { Luminal A vs. luminal B, } \mathrm{p}=0.0028 \text {; luminal A vs. Her2/neu overexpression, } \mathrm{p}<0.0001 \text {; luminal A vs. TNBC, } \mathrm{p}=0.0168 \text {; } \\
\text { Luminal B vs. Her2/neu overexpression, NS; luminal B vs. TNBC, NS; Her2/neu overexpression vs. TNBC, NS }\end{array}$} \\
\hline \multicolumn{3}{|l|}{$\mathrm{SLN+}$} \\
\hline 1 & 196 & $130.4(64.45-196.36)$ \\
\hline 2 & 50 & $180(24.93-335.06)$ \\
\hline \multicolumn{3}{|l|}{1 vs. 2 , NS } \\
\hline \multicolumn{3}{|l|}{ ECE } \\
\hline No & 132 & $94.46(41.09-147.83)$ \\
\hline Yes & 114 & $193.77(77.67-309.88)$ \\
\hline \multicolumn{3}{|l|}{ No vs. Yes, NS } \\
\hline \multicolumn{3}{|l|}{$\mathbf{S L N}_{\text {Dmax }}$} \\
\hline $2-5 \mathrm{~mm}$ & 96 & $50.21(19.89-80.53)$ \\
\hline$>5 \mathrm{~mm}$ & 150 & $198.26(101.11-295.41)$ \\
\hline $2-5 \mathrm{~mm}$ vs. $>5 \mathrm{~mm}, \mathrm{p}=0$. & & \\
\hline
\end{tabular}

$\mathrm{V}_{\mathrm{ALN}}$ - tumour volume in remaining axillary lymph nodes $\left[\mathrm{mm}^{3}\right]$; $\mathrm{pT} 1 \mathrm{a}-\mathrm{b}$ - primary tumour diameter < $10 \mathrm{~mm}$; $\mathrm{pTc}$ - primary tumour diameter 10-20 mm; PT2 - primary tumour diameter $>20 \mathrm{~mm}$; NST I - $\mathrm{t}$ - no special type grade 1 and tubular cancer; NST II — no special type grade 2; NST III — no special type grade 3; ER — oestrogen receptor; Her2/neu — Her2/neu receptor overexpression; SLN+ — number of positive sentinel lymph nodes; ECE — extracapsular extension; $\mathrm{SLN}_{\mathrm{Dmax}}$ - maximal diameter of metastasis in sentinel lymph node 
A vs. luminal B vs. Her2/neu overexpression vs. triple-negative breast cancer), number of involved SLN (1 vs. 2), SLN extracapsular extension (no vs. yes), and $\operatorname{SLN}_{\text {Dmax }}(2-5 \mathrm{~mm} v s .>5 \mathrm{~mm})$. The difference was significant if the $\mathrm{p}$ value was less than 0.05 .

We defined luminal tumours as those with oestrogen and progesterone receptors with no Her-2/neu receptor overexpression. Those with proliferative index value above median or progesterone receptors level below $20 \%$ or high grade were defined as luminal B. Her $2 /$ neu overexpression breast cancers were those with receptor overexpression in either immunochemistry or genetic testing. Those with neither expression of hormonal nor Her-2/neu receptors were defined as triple negative breast cancers.

Statistical analyses were performed using MedCalc for Windows, version 14.10.2 (MedCalc Software, Ostend, Belgium).

We calculated the local control probability (LCP) in the ALN for different molecular types (Tab. 2). For every patient the values of $\mathrm{V}_{\text {ALN }}$ were converted into the number of cancer cells $\left(\mathrm{N}_{\mathrm{BC}}\right)$ based on formula that $1 \mathrm{~mm}^{3}$ tumour harbours $10^{6}$ cancer cells [10].

$$
N_{B C}=V_{A L N} \times 10^{6}
$$

We considered that all patients with Her2/neu overexpression and triple-negative breast cancer would undergo chemotherapy and we defined that the treatment leads to a decrease in number of cancer cells by a factor of $10^{3}$, and for those with luminal $\mathrm{A}$ and $\mathrm{B}$ tumours, the decrease was set at $10^{2}$. The number of cells surviving chemotherapy $\left(\mathrm{N}_{\mathrm{chBC}}\right)$ were calculated following the formulas below:

Chemotherapy TNBC or Her2/neu overexpression:

$$
N_{c h B C}=N_{B C} \times 10^{-3}
$$

Chemotherapy luminal A or B tumours:

$$
N_{c h B C}=N_{B C} \times 10^{-2}
$$

No chemotherapy:

$$
N_{c h B C}=N_{B C}
$$

Classical fractionation scheme of postoperative irradiation is 25 fractions of 2 Gy per fraction. 2 Gy surviving fraction $\left(\mathrm{SF}_{2 \mathrm{~Gy}}\right)$ expresses percentage of cancer cells surviving one fraction

\begin{tabular}{|c|c|c|c|c|c|c|c|c|c|c|}
\hline Molecular type & & Mean $\mathbf{V}_{\text {ALN }}$ & $\mathbf{N}_{\mathrm{BC}}$ & CHth & $\mathbf{N}_{\text {chBC }}$ & $\begin{array}{c}S F_{2 G y}= \\
0.45^{\mathrm{e}}\end{array}$ & $\mathbf{N}$ & LCP & HTH & $\operatorname{axLCP}$ \\
\hline Luminal A & 90 & $\begin{array}{c}30.17 \\
(7.01-53.34)\end{array}$ & $3.01 \times 10^{7}$ & No & $3.01 \times 10^{7}$ & $2.14 \times 10^{-9}$ & $6.44 \times 10^{-2}$ & $93.8 \%$ & $10 \%$ & $99.9 \%$ \\
\hline Luminal B & 73 & $\begin{array}{c}263.74 \\
(95.83-431.65)\end{array}$ & $2.63 \times 10^{8}$ & No & $2.63 \times 10^{8}$ & $2.14 \times 10^{-9}$ & $5.63 \times 10^{-1}$ & $57 \%$ & $10 \%$ & $67 \%$ \\
\hline Luminal B & 73 & $\begin{array}{c}263.74 \\
(95.83-431.65)\end{array}$ & $2.63 \times 10^{8}$ & Yes & $2.63 \times 10^{6}$ & $2.14 \times 10^{-9}$ & $5.63 \times 10^{-3}$ & $99.4 \%$ & $10 \%$ & $99.9 \%$ \\
\hline $\begin{array}{l}\text { Her2/neu } \\
\text { overexpression }\end{array}$ & 37 & $\begin{array}{c}173.09 \\
(89.96-256.22)\end{array}$ & $1.73 \times 10^{8}$ & Yes & $1.73 \times 10^{5}$ & $2.14 \times 10^{-9}$ & $3.7 \times 10^{-4}$ & $99.9 \%$ & No & $99.9 \%$ \\
\hline $\begin{array}{l}\text { Her2/neu } \\
\text { overexpression }\end{array}$ & 37 & $\begin{array}{c}173.09 \\
(89.96-256.22)\end{array}$ & $1.73 \times 10^{8}$ & No & $1.73 \times 10^{8}$ & $2.14 \times 10^{-9}$ & $3.7 \times 10^{-1}$ & $69.1 \%$ & Yes & $79.1 \%$ \\
\hline $\begin{array}{l}\text { Her2/neu } \\
\text { overexpression }\end{array}$ & 37 & $\begin{array}{c}173.09 \\
(89.96-256.22)\end{array}$ & $1.73 \times 10^{8}$ & No & $1.73 \times 10^{8}$ & $2.14 \times 10^{-9}$ & $3.7 \times 10^{-1}$ & $69.1 \%$ & No & $69.1 \%$ \\
\hline TNBC & 24 & $\begin{array}{c}233.75 \\
(-93.82-561.33)\end{array}$ & $2.33 \times 10^{8}$ & Yes & $2.33 \times 10^{5}$ & $2.14 \times 10^{-9}$ & $4.99 \times 10^{-4}$ & $99.9 \%$ & No & $99.9 \%$ \\
\hline TNBC & 24 & $\begin{array}{c}233.75 \\
(-93.82-561.33)\end{array}$ & $2.33 \times 10^{8}$ & No & $2.33 \times 10^{8}$ & $2.14 \times 10^{-9}$ & $4.99 \times 10^{-1}$ & $60.7 \%$ & No & $60.7 \%$ \\
\hline
\end{tabular}
of 2 Gy irradiation. We set it at 0.45 . Following

Table 2. Local control probability in axilla for different molecular types and after division into low and high-risk luminal breast cancers

$V_{A L N}$ - tumour volume in remaining axillary lymph nodes $\left(\mathrm{mm}^{3}\right) ; \mathrm{N}_{\mathrm{BC}}$ - number of breast cancer cells correlated with tumour volume $\left(\mathrm{VALN}=1 \mathrm{~cm}^{3}\right.$ harbours $10^{6}$ breast cancer cells); $\mathrm{CHth}$ - chemotherapy; $\mathrm{N}_{\mathrm{chBC}}$ - number of breast cancer cells after chemotherapy (depleted by $10^{3}$ for Her $2 /$ neu overexpression and triple negative breast cancer, by $10^{2}$ for luminal tumours); SF2Gy $=0.45-$ depletion level of breast cancer cells number for $2 \mathrm{~Gy}$ surviving fraction equal to 0.45 ; $\mathrm{N}-$ mean number of cancer cells in axilla after chemotherapy and irradiation; LCP — local control probability in axilla following chemotherapy and radiotherapy, calculated using the formula $\mathrm{LCP}=\mathrm{e}^{-\mathrm{N}} ; \mathrm{HTH}$ - hormonotherapy and its influence on $\mathrm{LCP}$; axLCP — local control probability in axilla for surviving fraction 2 Gy equal to 0.45 ; TNBC — triple negative breast cancer 
Table 3. Local control probability in axilla for different molecular types and different radiation sensitivity values

\begin{tabular}{|c|c|c|c|c|c|c|c|c|}
\hline Molecular type & & Mean $V_{\text {ALN }}$ & $\mathrm{N}_{\mathrm{BC}}$ & Chth & HTH & $\begin{array}{c}\operatorname{axLCP} \\
(\mathrm{SF}=0.45)^{\mathrm{e}}\end{array}$ & $\begin{array}{c}\operatorname{axLCP} \\
(\mathrm{SF}=0.5)\end{array}$ & $\begin{array}{c}\operatorname{axLCP} \\
(\mathrm{SF}=0.6)\end{array}$ \\
\hline Luminal A & 90 & $30.17(7.01-53.34)$ & $3.01 \times 10^{7}$ & No & Yes & $99.9 \%$ & $50.9 \%$ & $10 \%$ \\
\hline Luminal B & 73 & $263.74(95.83-431.65)$ & $2.63 \times 10^{8}$ & No & Yes & $67 \%$ & $10 \%$ & $10 \%$ \\
\hline Luminal B & 73 & $263.74(95.83-431.65)$ & $2.63 \times 10^{8}$ & Yes & Yes & $99.9 \%$ & $99.9 \%$ & $10 \%$ \\
\hline Her2/neu overexpression & 37 & 173.09 (89.96-256.22) & $1.73 \times 10^{8}$ & Yes & No & $99.9 \%$ & $99.5 \%$ & $61.3 \%$ \\
\hline TNBC & 24 & $233.75(-93.82-561.33)$ & $2.33 \times 10^{8}$ & Yes & No & $99.9 \%$ & $99.3 \%$ & $51.2 \%$ \\
\hline
\end{tabular}

$\mathrm{V}_{\mathrm{ALN}}$ - tumour volume in remaining axillary lymph nodes; $\mathrm{N}_{\mathrm{BC}}$ - number of breast cancer cells correlated with tumour volume $\left(\mathrm{VALN}=1 \mathrm{~cm}^{3}\right.$ harbours $10^{6}$ breast cancer cells); $\mathrm{CH}$ th — chemotherapy; $\mathrm{HTH}$ - hormonal treatment; axLCP(SF=0.45) - local control probability in axilla for surviving fraction $2 \mathrm{~Gy}$ equal to 0.45 ; $\operatorname{axLCP}(S F=0.5)$ - local control probability in axilla for surviving fraction $2 \mathrm{~Gy}$ equal to 0.5 ; axLCP(SF=0.6) - local control probability in axilla for surviving fraction 2 Gy equal to 0.6 ; TNBC — triple negative breast cancer

the above assumption the number of cancer cells in tumour is reduced by $0.45^{25}$ and it is $2.14 \times 10^{9}$. Twenty-five $2 \mathrm{~Gy}$ fractions reduce the number of cancer cells by a factor of $2.14 \times 10^{9}$. The mean number of surviving cancer cells $(\mathrm{N})$ is expressed by the formula:

$$
N=N_{c h B C} \times 2.14 \times 10^{-9}
$$

The risk of relapse (LCP) in the axilla depends on $\mathrm{N}$ value and is expressed by the formula:

$$
L C P=e^{-N}
$$

For those patients with the presence of positive oestrogen receptors in the tumour, we calculated the expected local control probability in the axilla (axLCP) by increasing the final value by $10 \%$.

Following presented methodology we calculated axLCP for moderately sensitive tumours $\left(\mathrm{SF}_{2 \mathrm{~Gy}}=0.5\right)$ and radiation resistant ones $\left(\mathrm{SF}_{2 \mathrm{~Gy}}=0.6\right)(\mathrm{Tab} .3)$.

\section{Results}

$\mathrm{V}_{\mathrm{ALN}}$ mean values differed significantly among NST grade II and grade III tumour types $(\mathrm{p}=0.0013), \mathrm{SLN}_{\mathrm{Dmax}} 2-5 \mathrm{~mm} v s .>5 \mathrm{~mm}$ $(\mathrm{p}=0.019)$, luminal A vs. luminal B $(\mathrm{p}=0.0028)$, Her $2 /$ neu overexpression $(p<0.0001)$, and triple-negative breast cancer $(\mathrm{p}=0.0168)$. The were no significant differences among different tumour diameters, NST grade I, lobular type, and other higher-grade NST tumours. ER and Her2/neu status did not impact mean $V_{\text {ALN }}$ values. Luminal B, Her2/neu overexpression, and triple-negative breast cancers did not differ significantly. The same result was observed for the number of involved SLNs and extracapsular extension (Tab. 1).

In radiation sensitive tumours $\left(\mathrm{SF}_{2 \mathrm{~Gy}}=0.45\right) \mathrm{ax}-$ LCP for Her-2/neu overexpression and triple-negative breast cancers is nearly $100 \%$ if chemotherapy and irradiation of the ALN is used after a positive SLNB, but with no chemotherapy it is only $69.1 \%$ (79.1\% with hormonal treatment) in Her $2 /$ neu overexpression and $60.7 \%$ in TNBC. For luminal A tumours axLCP is nearly $100 \%$ if irradiation and hormonal treatment is used. In luminal B tumours axLCP is $67 \%$ with irradiation and hormonal treatment only and increases to nearly $100 \%$ for chemotherapy use (Tab. 2).

In moderately sensitive tumours the axLCP is high, nearly $100 \%$, for Her- $2 /$ neu overexpression, triple-negative and luminal B breast cancers if chemotherapy and radiotherapy is used. For luminal A it drops to nearly $50 \%$ if only radiotherapy and hormonal treatment is used (Tab. 3). In radiation resistant tumours the axLCP values are low for all tumour types (from 10\% for luminal tumours to 61.3\% for Her-2/neu overexpression) (Tab. 3).

\section{Discussion}

In the present study, we showed that $\mathrm{V}_{\mathrm{ALN}}$ is correlated with the molecular type, high grade, and $\mathrm{SLN}_{\text {Dmax }}$ after positive SLNB. $\mathrm{V}_{\mathrm{ALN}}$ is a predictive factor for locoregional treatment results that are reflected by axLCP. It is also influenced by radiation sensitivity, systemic treatment (chemotherapy, hormonal treatment), and irradiation (dose, fractionation). A combined effect of those factors resulted in a low axillary recurrence rate in the ACOSOG Z0011 and AMAROS trials (1.5\% and 1.19\%, respectively) $[5,6]$. Breast cancer patients with mac- 
rometastases in one or two SLNs may be spared ALND in favour of irradiation, based on the results of those trials $[7,8]$.

In both trials, one or two positive SLNs were present in nearly $60 \%$ of enrolled breast cancer patients. Considering that $40 \%$ of all patients had micrometastases or isolated tumour cells in SLNs and that two-thirds of all enrolled patients underwent chemotherapy, it is possible that most patients with one or two positive SLNs underwent chemotherapy. The current recommendations lead to less frequent use of chemotherapy in luminal-type breast cancer patients with metastases in 1-3 axillary lymph nodes [7, 8]. There are no data whether less frequent use of chemotherapy influences local treatment results in patients with metastases in 1-2 SLNs. There are limited data on predictive factors for the pathological stage $\mathrm{pN} 2$ or $\mathrm{pN} 3$ after ALND that follows a positive SLNB $[11,12]$.

Based on current recommendations for chemotherapy use, we estimated axLCP. The calculations were based on mean values of $\mathrm{V}_{\mathrm{ALN}}$ and molecular types of breast cancer. We made some assumptions. We assumed that chemotherapy decreases the number of breast cancer cells by a factor of $10^{3}$ in non-luminal types and by a factor of $10^{2}$ in luminal types of tumours. Schipper et al. [13] analysed the frequency of axillary lymph node pathological complete remission in the group of patients who had undergone neoadjuvant chemotherapy without or with trastuzumab (for Her-2 receptor overexpression). They reported a $50 \%$ pathological complete remission rate for triple-negative tumours and $47.5-56.6 \%$ for those with Her-2 receptor overexpression. There was only $15.4 \%$ of axillary lymph nodes complete pathological remission in luminal-type tumours [13]. One $\mathrm{cm}^{3}$ mass is thought to be occupied by $10^{9}$ cells, as subclinical disease is occupied by no more than $10^{6}$ cancer cells [10]. The probability of local control $(\mathrm{P})$ depends on the mean value of the surviving clonogen cells $(\mathrm{N})$ : $\mathrm{P}=\mathrm{e}^{-\mathrm{N}}$. Then $\mathrm{N}$ may be calculated: $\mathrm{N}=\ln _{\mathrm{P}}$ Given that $50 \%$ pathological complete remission occurs after chemotherapy in non-luminal tumours, and $15 \%$ occurs for luminal tumours, the $\mathrm{N}$ value was 0.69 for non-luminal and 1.89 for luminal tumours. The estimated mean number of clonogen cells before chemotherapy $\left(10^{4}-10^{5}\right)$ allows estimation of the decrease of the mean $\mathrm{N}$ value by a factor $10^{3}$ for triple-negative, Her-2/neu overexpressing tumours, and $10^{2}$ for luminal-type tumours.

We assumed that hormonal treatment increases predicted axLCP by $10 \%$. Wazer et al. [14] reported that adding tamoxifen to irradiation improved 10 -y local control by $91.6 \%$ to $98.1 \%$ in breast cancer patients who had undergone breast conserving surgery. In a comparable group, $\mathrm{Bu}$ cholz et al. [15] showed improved 8-y local control $(95.6 \% v$ v. $85.2 \%)$ in patients who had undergone systemic treatment compared to those who had been spared it.

Ruka et al. [16] estimated the radiosensitivity of breast cancer cells. It was expressed by the number of cells surviving a dose of $2 \mathrm{~Gy}\left(\mathrm{SF}_{2 \mathrm{~Gy}}\right)$. The obtained values ranged from 0.23 to 0.54 (mean 0.38). Speers et al. [17] showed no difference in the $\mathrm{SF}_{2 \mathrm{~Gy}}$ value among different molecular types of breast cancer, with values ranging from $17 \%$ to $77 \%$. They defined tumours with $\mathrm{SF}_{2 \mathrm{~Gy}} 0.45$ or below to be radiation sensitive [18]. For the purpose of this study, we set also the value of $\mathrm{SF}_{2 \mathrm{~Gy}}$ to 0.45 for radiation sensitive tumours, which means that $45 \%$ of breast cancer cells survive every fraction of 2-Gy irradiation. The common fractionation scheme is 25 daily doses of $2 \mathrm{~Gy}$. The mean number of surviving clonogen cells $(\mathrm{N})$ is expressed by the formula $\mathrm{N}=0.45^{25}$, and the value obtained was $2.14 \times 10^{-9}$.

One may discuss whether the assumptions we make are reliable. The study is not intended to draw final conclusions. The relationships we present are significant in selected prognostic factors. $\mathrm{V}_{\mathrm{ALN}}$ values are higher for high grade tumours and larger metastases in SLNs. $\mathrm{V}_{\mathrm{ALN}}$ is smaller for luminal A tumours.

The number of axillary relapses was low in the ACOSOG Z0011 and AMAROS trials [5, 6]. Nevertheless, it does not allow us to resign searching for risk factors of relapses. Almost $50 \%$ of patients with axillary recurrences after negative sentinel lymph node biopsy develop distant metastases and only $58 \%$ survive 5 years since relapse [18]. Selecting those who benefit from ALND may be important. Expected axLCP suggests that the number of those who might benefit from ALND is small.

Following present recommendations, most breast cancer patients with clinically negative axilla and either triple negative or Her-2/neu overexpressing tumours are going to be given neoadjuvant systemic treatment $[7,8]$. Nowadays, the ACOSOG 
Z0011 and AMAROS trials considerations rarely apply to those patients. Luminal A tumours are radiation sensitive as presented in the study by Laurberg et al. [19]. They analysed data from two independent post-mastectomy trials (British Columbia and Danish Breast Cancer Cooperative Group 82b) and showed the biggest benefit from adjuvant radiotherapy in patients with luminal A type breast cancers. In this group of patients irradiation with hormonal treatment might be enough.

Breast cancer patients with luminal B tumours seem to be at the highest risk of relapse in the axilla if they are not given adjuvant chemotherapy. As we mentioned earlier, nowadays less luminal B patients are qualified for adjuvant chemotherapy, as not every patient with positive SLN is going to be in stage $\mathrm{pN} 2$ or $\mathrm{pN} 3$. In our group only 23 (31.5\%) luminal $\mathrm{B}$ patients were $\mathrm{pN} 2$ or $\mathrm{pN} 3$. It seems we need additional prognostic factors in this group of patients to spare them ALND and adjuvant chemotherapy. Adjuvant irradiation and hormonal therapy might not be enough to prevent relapse in the axillary lymph nodes.

\section{Conclusions}

$\mathrm{V}_{\mathrm{ALN}}$ values differ among molecular tumour types. They also depend on $\mathrm{SLN}_{\text {Dmax }}$ and tumour grade in patients with one or two macrometastases in SLN. We need new prognostic factors for selected luminal B breast cancer patients (i.e. high grade tumours, large metastases in SLNs) after positive SLNB intended to be spared ALND and chemotherapy.

\section{Conflict of interest}

The authors declare that they have no conflicts of interest.

\section{Funding}

This research did not receive any specific grant from funding agencies in the public, commercial, or not-for-profit sectors.

\section{Ethical approval}

This article is a retrospective cohort data analysis of patients who were routinely treated in our institution in accordance with ethical standards of our institution and current medical knowledge.

\section{Informed consent}

There was no need to obtain informed consent from individual participants, because only retrospective data were analysed - available from hospital records.

This research did not receive any specific grant from funding agencies in the public, commercial, or not-for-profit sectors.

\section{References}

1. Hunt KK, Ballman KV, McCall LM, et al. Factors associated with local-regional recurrence after a negative sentinel node dissection: results of the ACOSOG Z0010 trial. Ann Surg. 2012; 256(3): 428-436, doi: 10.1097/ SLA.0b013e3182654494, indexed in Pubmed: 22868365.

2. Mansel RE, Fallowfield L, Kissin M, et al. Randomized multicenter trial of sentinel node biopsy versus standard axillary treatment in operable breast cancer: the ALMANAC Trial. J Natl Cancer Inst. 2006; 98(9): 599-609, doi: 10.1093/ jnci/djj158, indexed in Pubmed: 16670385.

3. Galimberti V, Cole B, Zurrida S, et al. Axillary dissection versus no axillary dissection in patients with sentinel-node micrometastases (IBCSG 23-01): a phase 3 randomised controlled trial. Lancet Oncol. 2013; 14(4): 297-305, doi: 10.1016/s1470-2045(13)70035-4, indexed in Pubmed: 23491275.

4. Solá M, Alberro JA, Fraile M, et al. Complete axillary lymph node dissection versus clinical follow-up in breast cancer patients with sentinel node micrometastasis: final results from the multicenter clinical trial AATRM 048/13/2000. Ann Surg Oncol. 2013; 20(1): 120-127, doi: 10.1245/ s10434-012-2569-y, indexed in Pubmed: 22956062.

5. Giuliano AE, Ballman K, McCall L, et al. Locoregional recurrence after sentinel lymph node dissection with or without axillary dissection in patients with sentinel lymph node metastases: the American College of Surgeons Oncology Group Z0011 randomized trial. Ann Surg. 2010; 252(3): 426-32; discussion 432, doi: 10.1097/ SLA.0b013e3181f08f32, indexed in Pubmed: 20739842.

6. Donker M, van Tienhoven G, Straver ME, et al. Radiotherapy or surgery of the axilla after a positive sentinel node in breast cancer (EORTC 10981-22023 AMAROS): a randomised, multicentre, open-label, phase 3 non-inferiority trial. Lancet Oncol. 2014; 15(12): 1303-1310, doi: 10.1016/ S1470-2045(14)70460-7, indexed in Pubmed: 25439688.

7. NCCN Clinical Practice Guidelines in Oncology (2019) Breast Cancer ver. 1. www.nccn.org/professionals/physician_gls/pdf/breast.pdf (14 March 2019).

8. Curigliano G, Burstein HJ, P Winer E, et al. Panel Members of the St. Gallen International Expert Consensus on the Primary Therapy of Early Breast Cancer 2017, St. Gallen International Expert Consensus on the Primary Therapy of Early Breast Cancer 2017. De-escalating and escalating treatments for early-stage breast cancer: the St. Gallen International Expert Consensus Conference on the Primary Therapy of Early Breast Cancer 2017. Ann Oncol. 2017; 28(8): 1700-1712, doi: 10.1093/annonc/mdx308, indexed in Pubmed: 28838210. 
9. Falco M, Masojć B, Byrski T, et al. The diameter of metastasis in positive sentinel lymph node biopsy affects axillary tumor load in early breast cancer. Asia Pac J Clin Oncol. 2019; 15(3): 121-127, doi: 10.1111/ajco.13113, indexed in Pubmed: 30761763.

10. Marks L. A standard dose of radiation for"microscopic disease" is not appropriate. Cancer. 1990; 66(12): 2498-2502, doi: 10.1002/1097-0142(19901215)66:12<2498::aidcncr2820661209>3.0.co;2-x, indexed in Pubmed: 2249190.

11. Katz A, Smith BL, Golshan M, et al. Nomogram for the prediction of having four or more involved nodes for sentinel lymph node-positive breast cancer. J Clin Oncol. 2008; 26(13): 2093-2098, doi: 10.1200/JCO.2007.11.9479, indexed in Pubmed: 18445838.

12. Piñero-Madrona A, Ruiz-Merino $G$, Bernet $L$, et al. Tumoral load quantification of positive sentinel lymph nodes in breast cancer to predict more than two involved nodes. Breast. 2014; 23(6): 859-864, doi: 10.1016/j. breast.2014.09.005, indexed in Pubmed: 25283682.

13. Schipper RJ, Moossdorff M, Nelemans PJ, et al. A model to predict pathologic complete response of axillary lymph nodes to neoadjuvant chemo(immuno)therapy in patients with clinically node-positive breast cancer. Clin Breast Cancer. 2014; 14(5): 315-322, doi: 10.1016/j. clbc.2013.12.015, indexed in Pubmed: 24548732.

14. Wazer DE, Morr J, Erban JK, et al. The effects of postradiation treatment with tamoxifen on local control and cosmetic outcome in the conservatively treated breast. Cancer. 1997; 80(4): 732-740, doi: 10.1002/(sici)1097- 0142(19970815)80:4<732::aid-cncr12>3.0.co;2-u, indexed in Pubmed: 9264357.

15. Buchholz TA, Tucker SL, Erwin J, et al. Impact of systemic treatment on local control for patients with lymph nodenegative breast cancer treated with breast-conservation therapy. J Clin Oncol. 2001; 19(8):2240-2246, doi: 10.1200/ JCO.2001.19.8.2240, indexed in Pubmed: 11304777.

16. Ruka W, Taghian A, Gioioso D, et al. Comparison between the in vitro intrinsic radiation sensitivity of human soft tissue sarcoma and breast cancer cell lines. J Surg Oncol. 1996; 61(4): 290-294, doi: 10.1002/(SICI)10969098(199604)61:4<290::AID-JSO13>3.0.CO;2-A, indexed in Pubmed: 8628001.

17. Speers C, Zhao S, Liu M, et al. Development and Validation of a Novel Radiosensitivity Signature in Human Breast Cancer. Clin Cancer Res. 2015; 21(16): 3667-3677, doi: 10.1158/1078-0432.CCR-14-2898, indexed in Pubmed: 25904749.

18. Bulte JP, van Wely BJ, Kasper S, et al. Long-term follow-up of axillary recurrences after negative sentinel lymph node biopsy: effect on prognosis and survival. Breast Cancer Res Treat. 2013; 140(1): 143-149, doi: 10.1007/s10549013-2608-9, indexed in Pubmed: 23793602.

19. Laurberg T, Tramm T, Nielsen T, et al. Intrinsic subtypes and benefit from postmastectomy radiotherapy in node-positive premenopausal breast cancer patients who received adjuvant chemotherapy - results from two independent randomized trials. Acta Oncol. 2018; 57(1): 38-43, doi: 10.1080/0284186X.2017.1401735, indexed in Pubmed: 29172851. 